\title{
TIDAL ACTIVITY RHYTHM OF THE HERMIT CRAB, PAGURUS GEMINUS MCLAUGHLIN
}

\author{
AUTHOR(S): \\ Imafuku, Michio
}

\section{CITATION:}

Imafuku, Michio. TIDAL ACTIVITY RHYTHM OF THE HERMIT CRAB, PAGURUS GEMINUS MCLAUGHLIN. PUBLICATIONS OF THE SETO MARINE BIOLOGICAL LABORATORY 1981, 26(4-6): 327-336

ISSUE DATE:

1981-09-30

URL:

http://hdl.handle.net/2433/176035

RIGHT: 


\title{
TIDAL AGTIVITY RHYTHM OF THE HERMIT CRAB, PAGURUS GEMINUS MCLAUGHLIN')
}

\author{
MichIo IMAFUKU \\ Department of Zoology, Faculty of Science, Kyoto University
}

With Text-figures $1-6$ and Table 1

Tidal rhythms are known in many animal and plant species living in intertidal zone (Palmer, 1974). One of interesting aspects concerning tidal rhythms is that animals living under the influence of an ordinary change of tide possess tidal rhythms while ones inhabiting shores of a small change of tide do not have rhythms of tidal frequency but of circadian frequency. This has been shown in the relative species of green crabs (Naylor, 1958; 1961), blennies (Gibson, 1965; 1969) and in the same species of fiddler crabs (Barnwell, 1968).

The present paper deals with the activity rhythm of the hermit crab, Pagurus geminus, which is one of the commonest inhabitants of Japanese littoral zone and is distributed all over Japan including the Pacific coast with the ordinary change of tide and the Japan Sea coast with the small change of tide.

\section{Material and Method}

The hermit crabs, Pagurus geminus Mclaughlin, obtained from the Pacific coast (Pacific crab) and the Japan Sea coast (Japan Sea crab) were employed. Pacific crabs were collected from shores near the Seto Marine Biological Laboratory in Shirahama and their locomotor activity was examined in the laboratory (Fig. 4). Japan Sea crabs were captured in beaches of Takahama, brought into the Fisheries Research Station in Maizuru through a two-hour trip by train and bus and immediately subjected to experiments. All the animals investigated were 5 to $9 \mathrm{~mm}$ in carapace length and males (this was due to easiness in recording because of their larger size than females).

The locomotor activity of hermit crabs was recorded as follows in both laboratories. One to four crabs were kept respectively in glass vessels $(12 \mathrm{~cm}$ in diameter, $6 \mathrm{~cm}$ high) in a 50 to 100 liter aquarium and their locomotor activity was respectively recorded on a kymograph rotating once a week as illustrated in Fig. 1. The sea water in the aquarium was slowly circulated within by aeration, which enabled animals maintaining their vivid conditions throughout the experimental periods of

1) Contributions from the Seto Marine Biological Laboratory, No. 676.

Publ. Seto Mar. Biol. Lab., XXVI (4/6), 327-336, 1981.

(Article 17) 


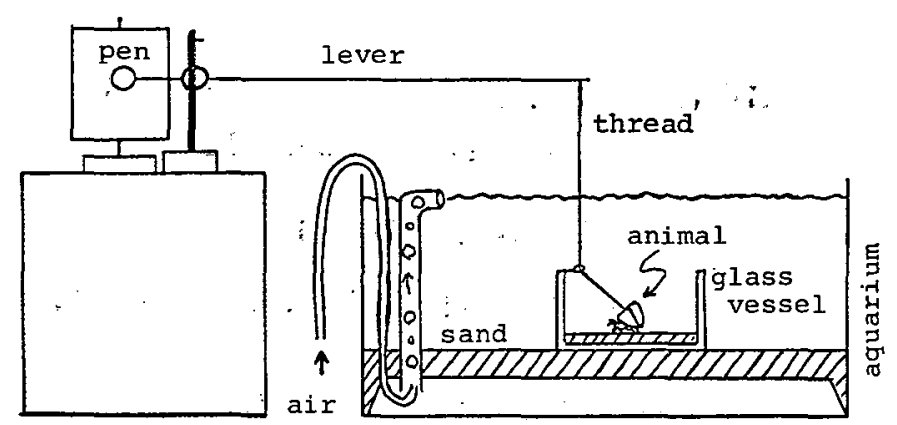

Fig. 1. Method for recording the locomotor activity of the hermit crab.

10 to 22 days without exchanging the water. Occasionally a bit of water lost by evaporation was compensated with the same volume of tap water. The water temperature in the aquarium was controlled to a constant one nearly equal to that of the sea water of the shore from which animals were collected. The light condition was either a constant dim light of approximately one lux produced by a midget lamp or the natural light entering through the windows of the room. Hermit crabs were never fed throughout the experimental period. The experiments were carried out in 1974.

\section{Results}

\section{Pacific crabs}

Two examples of the activity rhythm in Pacific crabs kept in the natural light are shown in Fig. 2. In both Crabs 16 and 19, the active phase, drawn by short vertical movements of a pen, almost always appears at the time when the beach is covered with flood tide, shown with small open circles, with a daily shift in consecutive days approximately in parallel with the daily delay of the tide. The result suggests that the hermit crabs have a tidal rhythm and are high water active. On the other hand, they seem not to have semilunar periodicity because the amount of activity. almost unchanges between around the time of the first quarter moon and the time of the full moon.

- Out of seven other Pacific crabs examined under the same condition as the two mentioned above, in the natural light, five individuals behaved almost similarly to the two example animals shown in Fig. 2, showing a clear activity rhythm for at least five days, with the peaks of the activity coinciding with the time of high water, while the remaining two displayed irregular activity from a few days after the initiation. of the experiment. Thus, $78 \%$ of Pacific crabs were found to show a clear activity rhythm under the condition of the natural light.

The behavior of six Pacific crabs was examined in the constant dim light. Two examples of them are shown in Fig. 3. In Crab 8, the active phase appears at the time of high water throughout the whole experimental period of 22 days. The period length of this individual was calculated to be 12.5 hours. In Crab 9, the 

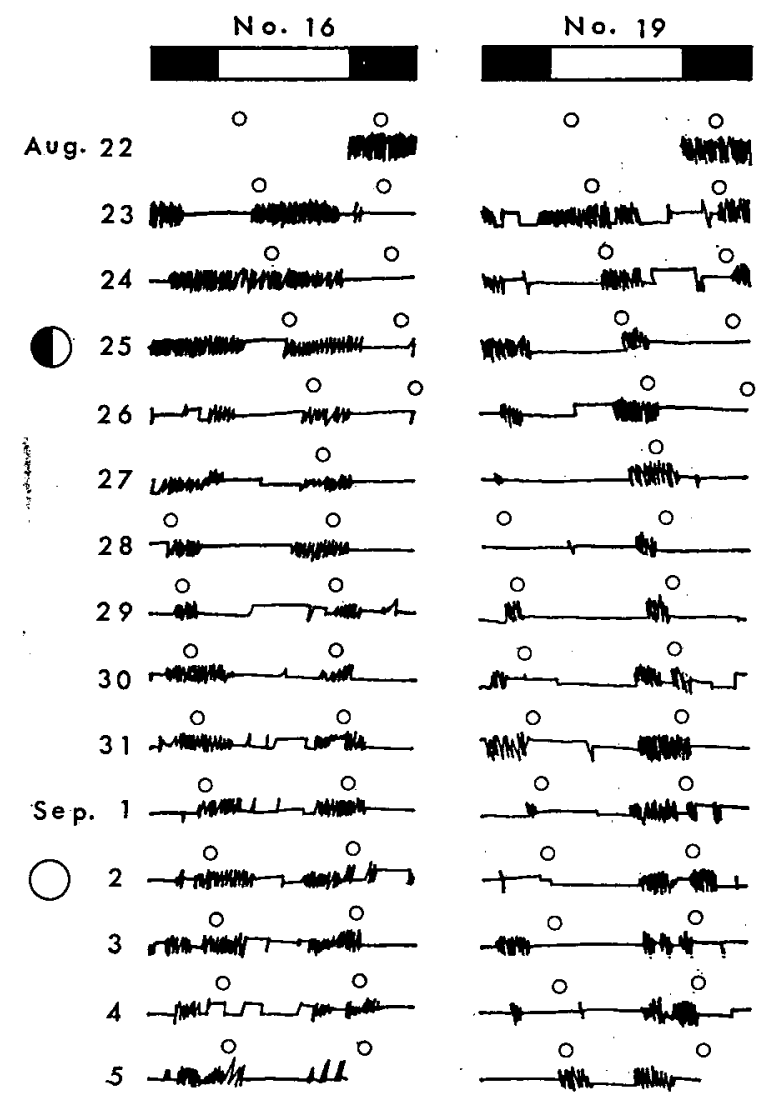

Fig. 2. Activity records of two Pacific crabs (no. 16 and no. 19) under the condition of the natural light. Active phase is drawn with a cluster of short vertical lines and quiescent phase with a smooth holizontal line. Time of flood tide on the shore is indicated with small open circles. Moon phase is shown with a large circle just before date; full moon with an open circle. The temperature of the water in the aquarium was $25.5-28.5^{\circ} \mathrm{C}$.

active phase coincides with the time of high water in the beginning of the experiment, but it becomes delayed gradually as days elasps and finally utterly out of phase with the tide from May 20 to 24 . And it again becomes surperimposed on the time of high water from May 27 to 30 as the result of one-cycle delay, then delay goes on further. The period length of Crab 9 was calculated to be 13.1 hours. Therefore, the period length was found to be different among individuals, suggesting that the cause of the rhythm is of endogenous nature.

Out of four other Pacific crabs investigated in the constant dim light, three expressed a clear rhythm with the period length $12.2,12.5$ and 12.5 hours respectively, and the remaining one was of irregular activity. Finally $83 \%$ of Pacific crabs showed a regular rhythm in the condition of constant dim light and the period length was 12.6 hours in average. 

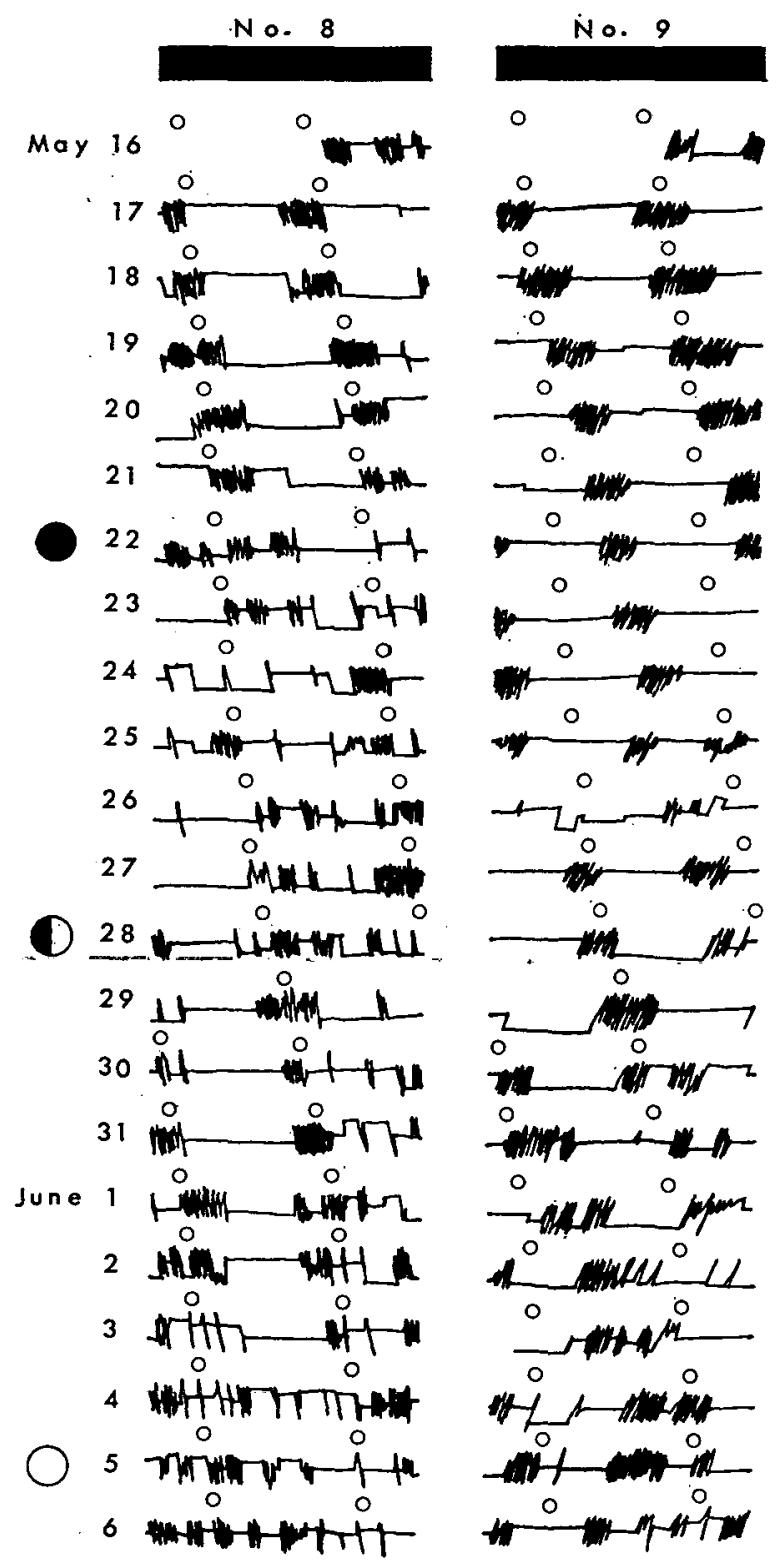

Fig. 3. Activity records of two Pacific crabs (no. 8 and no. 9) under the condition of constant dim light. The temperature was 20.4$22.1^{\circ} \mathrm{C}$.

\section{Japan Sea crabs}

In the Japan Sea the range of tide is known to be very small as referred to Fig. 4 which gives schematical illustrations of the tidal changes on coasts of Maizuru and Shirahama from July 13 to 26 in 1974. Seven individuals of Japan Sea crabs were investigated in the natural light and four were in the constant dim light. 


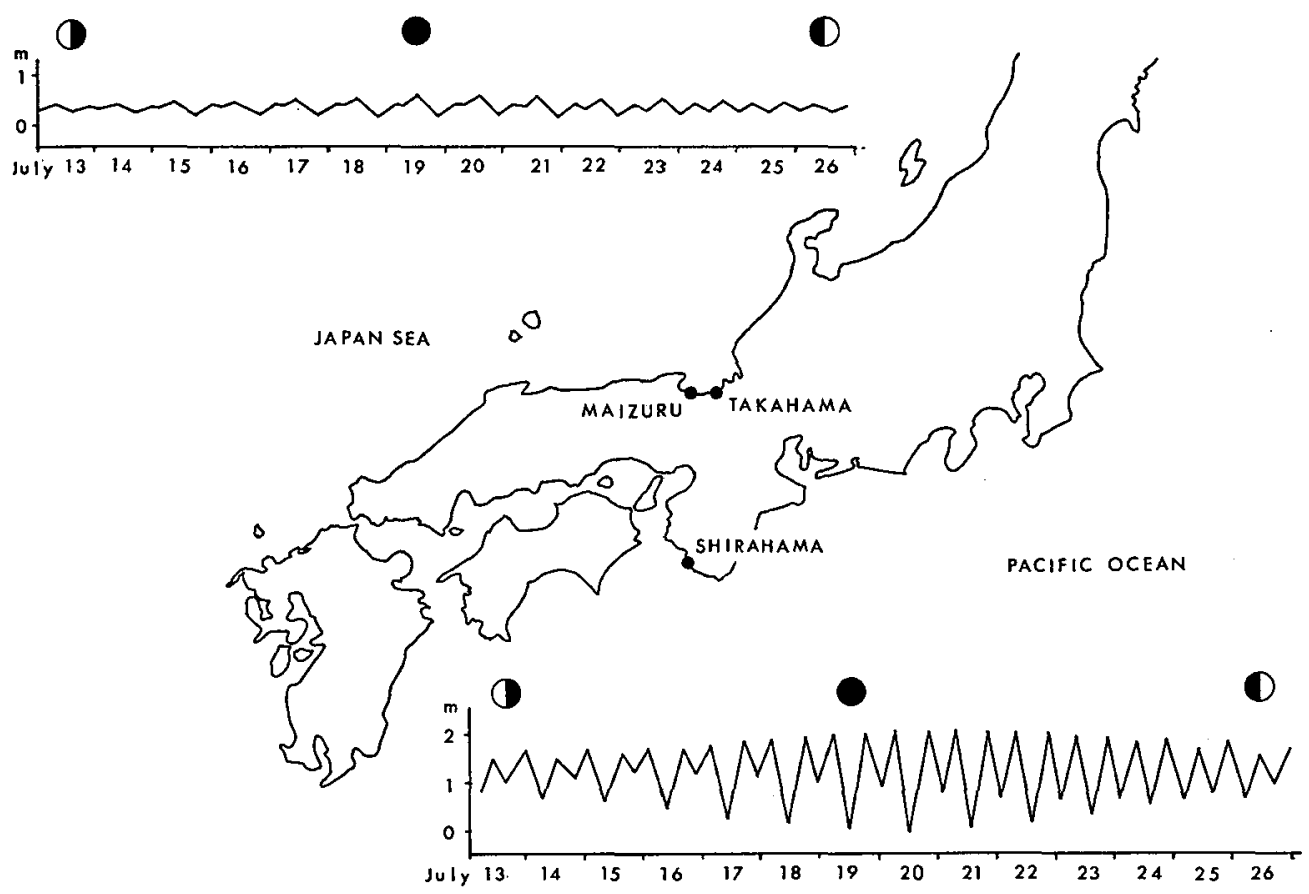

Fig. 4. Tidal change at Maizuru on the Japan Sea coast (above) and at Shirahama on the Pacific coast (below). Graphs are made from the Tide Table of 1974.

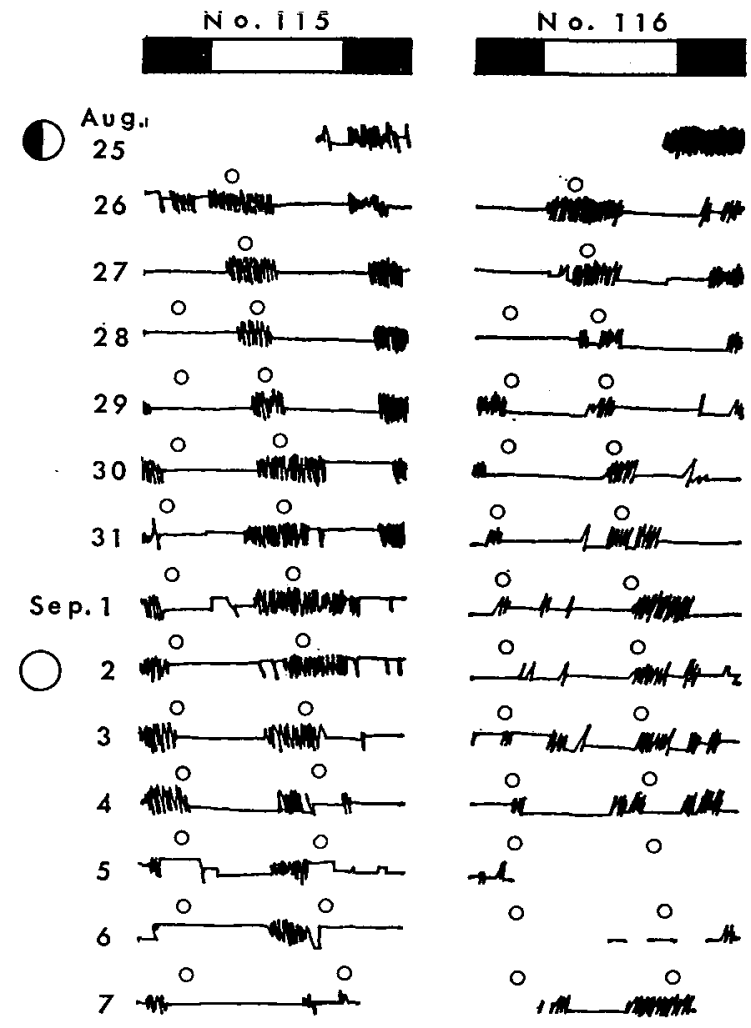

Fig. 5. Activity records of two Japan Sea crabs (no. 115 and no. 116) under the condition of the natural light. The temperature was $25.9-28.1^{\circ} \mathrm{C}$. 
In the natural light, five individuals out of seven Japan Sea crabs exhibited a clear activity rhythm in which the active phase appeared at a fairly stable interval, the daytime peak being superimposed on the time of high water while the nighttime one not always coinciding with it, as seen in two examples of Crabs 115 and 116 shown in Fig. 5. The remaining two individuals out of seven Japan Sea crabs examined in the natural light displayed irregular activity without showing any clear relation between the active phase and the state of the tide. Thus, $71 \%$ of Japan Sea crabs were found to show a clear rhythm in the natural light.

Figure 6 shows the records of Crabs 111 and $112 \mathrm{kept}$ in the constant dim light. In these two animals, a rather regular activity rhythm is seen, especially in Crab 111 in which the active phase appears twice a day almost without daily shift. The period length of this individual was calculated to be 12.0 hours. In Crab 112, the activity rhythm becomes somewhat obscure from August 14 to 17 but it reappears clearly after August 18 with a period length of 12.6 hours. Two other individuals of Japan Sea crabs examined in the condition of the constant dim light expressed a

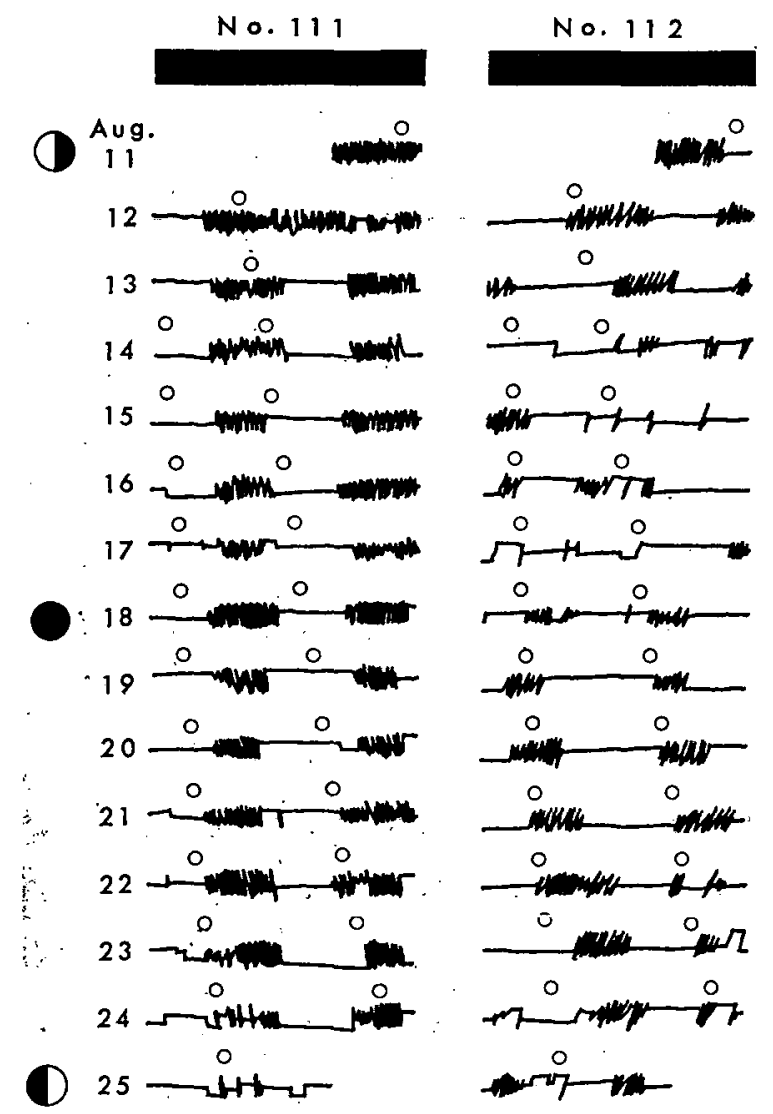

Fig. 6. Activity records of two Japan Sea crabs (no. 111 and no. 112) under the condition of constant dim light. The temperature was $28.0-28.5^{\circ} \mathrm{C}$. 
clear rhythm which persisted for the whole experimental period of 15 days with a period length of 12.0 hours in one individual and for the first seven days of the experimental period with a period length of 12.5 hours in the other. Thus, all individuals examined in the constant dim light displayed a clear rhythm and the period length was 12.3 hours in average.

\section{Discussion}

The activity rhythm of the hermit crab, Pagurus geminus, was investigated in two different places with respect to tidal condition and it was clarified in both places that the hermit crabs possess a rhythm with two peaks a day, though some individual difference in regularity or persistency of the rhythm was observed. The rate at which the animal showing regular rhythm appears is summarized in Table 1 where the

Table 1. Rate of the animal showing regular rhythm (numerator) to the animal examined (denomiantor) in the natural light (LD) and constant dim light condition (DD) at two different places.

\begin{tabular}{|c|c|c|c|}
\hline . & LD & $\mathrm{DD}$ & total \\
\hline Pacific crab & $7 / 9 \quad(78 \%)$ & $5 / 6 \quad(83 \%)$ & $12 / 15(80 \%)$ \\
\hline Japan Sea crab & $5 / 7 \quad(71 \%)$ & $4 / 4 \quad(100 \%)$ & $9 / 11(82 \%)$ \\
\hline total & $12 / 16(75 \%)$ & $9 / 10(90 \%)$ & $21 / 26(81 \%)$ \\
\hline
\end{tabular}

animal persisting its rhythm for more than five days is regarded as of regular rhythm. By statistical analysis no significant difference in the appearance of animals with regular rhythm could be found between Pacific crabs and Japan Sea crabs nor between the condition of the natural light and the constant dim light. That is, animals with irregular activity appeared at a rate of less than $30 \%$ in each population or each condition in the present experiments. The individual difference in the expression of regular rhythm has been observed in some other species. For example, about $50 \%$ of fiddler crabs examined were found to be of irregular activity (Honegger, 1973), and some types of irregular behaviors were observed in the contraction-expansion rhythm of the sea-pen (Imafuku, 1973).

The cause of the rhythm in the hermit crab is thought to be attributable to endogenous component but not to exogenous one because the rhythm persisted in the constant dim light for several days with individual difference in the period length even in some animals kept simultaneously in the same condition (Figs. 3 and 6). If the cause of the rhythm is exogenous, all hermit crabs kept in a same condition would behave synchronously with a common period length. In addition, the fact that some hermit crabs kept in a single aquarium under the condition of constant dim light expressed respectively their own period length eliminates the possibility of mutual entrainment among them.

The next problem to be answered is to what kind the endogenous rhythm of the hermit crab should belong, tidal or circadian. Circadian rhythms are sometimes 
of bimodal, with two peaks a day (Aschoff, 1966), so that the period length of such circadian rhythms may be calculated to be approximately 12 hours, the value undistinguishable from that of tidal ones widely known as about 12.4 hours. Therefore, as long as the period length is exclusively taken into consideration, the discrimination on the kind of rhythm may be difficult. However, when the phase of rhythm is closely examined, the problem may be easily dissolved. It is generally known that in circadian rhythms of bimodal pattern two active phases appear at around dawn and dusk, while in tidal rhythms two peaks occur at a certain state of tide such as low water or high water regardless of the natural light. In the case of the hermit crab, the active phase appeared coinciding with the time of high water on the coast (Figs. 2, 3, 5 and 6), especially in the beginning of the experiment. Another evidence supporting the rhythm of the hermit crab being tidal, is that the active phase would not be fixed to sunrise nor sunset even in a long term of sojourn in the natural light and that their period length would not come to just 12 nor 24 hours. Therefore, the rhythm observed in the hermit crab could be concluded to be tidal.

Now the activity rhythm of the hermit crab was clarified to be tidal, and this was applicable to Japan Sea crabs living on the coast with the small change of tide. Similar comparative studies have been performed on some other animal species. The green crab, Carcinus maenas, from the British coast where the range of tide is big (ca. $860 \mathrm{~cm}$ ) showed a complex activity with tidal frequency and daily frequency (Naylor, 1958), while crabs of the same species from non-tidal dock (Naylor, 1960) and the relative species, $C$. mediterraneus, from the bay of Naples where the range of tide is very small (Naylor, 1961) exhibited only a circadian rhythm. The same was also found in the littoral fish. Blennius pholis from the British coasts displayed a tidal rhythm (Gibson, 1965), while $B$. guttorine and B. sanguinolentus from the Mediterranean coasts showed a rhythm with two peaks corresponding respectively with dawn and dusk (Gibson, 1969). In the unknown species of fiddler crab, Uca, a daily rhythm was recorded on specimens collected from the non-tidal habitat of Biloxi Bay, while it was modified into a tidal one by exposing crabs to the ordinary change of tide at Woods Hole for at least 22 days (Barnwell, 1968). In all these cases, animals in a small change of tide or non-tidal conditions displayed daily or circadian rhythms, while ones in an ordinary change of tide exhibited tidal rhythms, the results contrary to the case of the hermit crabs which exhibited a tidal rhythm regardless of the range of tide on the habitat.

It may be natural that animals living under non-tidal conditions, such as the green crabs from the floating dock and the $U c a$ species in Biloxi Bay, have no tidal rhythms. On the other hand, out of animais iiving under the condition of a smaii change of tide, Mediterranean species possess no tidal rhythms while Japan Sea hermit crab has the tidal rhythm. The difference could not be attributable to the difference in the range of tide between two seas, because it does not so much differ; the range of tide at spring tides is $43 \mathrm{~cm}$ at Naples where the green crabs, $C$. mediterraneus were investigated and of the order of $18 \mathrm{~cm}$ at the Laboratoire Arago, Banyuls-sur-Mer where the Mediterranean blennies were studied, while it is about $40 \mathrm{~cm}$ at Maizuru on 
the Japan Sea coast. Or rather, the difference may be derived from the difference in the habitat of animals. The hermit crabs were found gathering in the so-called intertidal zone on the Japan Sea coast, though it is very narrow on the water's edge, probably undergoing the regular repetition of the small change of tide, while Mediterranean animals may inhabit relatively widely, including the subtidal zone.

Another interesting phenomenon on the tidal rhythm of the hermit crab is that the animals seem not to have a complicated plan of the activity. The tidal change is known to be somewhat distorted; the time between two consecutive high waters sometimes more or less deviates from 12.4 hours especially in the Japan Sea, as seen in Figs. 5 and 6 . When the behavior of the hermit crab of the Japan Sea is closely examined, the activity is found to appear at a relatively constant interval without closely following the distorted change of tide. Therefore, it seems likely that the hermit crab possesses a simple clock whose period length is approximately 12.4 hours. This contrasts to the behavior of other intertidal animals (Enright, 1963).

\section{Acknowledgments}

The present author wishes to express his sincere gratitude to the staff of the Seto Marine Biological Laboratory and of the Fisheries Research Station, for affording the author every facility for the works at the laboratories, and to Mr. Mbomba Nseu Bekeli of the Kyoto University for reading the manuscript.

\section{Summary}

The locomotor activity of the hermit crab, Pagurus geminus, was investigated at two different places with respect to tidal conditions, one on the Pacific coast with the ordinary change of tide and the other on the Japan Sea coast with the small change of tide. In both places it was found that the hermit crab possesses the endogenous tidal rhythm and is high water active. Some discussions are made on the result in comparison with those obtained on other animal species in similar experiments.

\section{REFERENGES}

Aschoff, J. 1966. Circadian activity pattern with two peaks. Ecology, 47: 657-662.

Barnwell, F.H. 1968. The role of rhythmic systems in the adaptation of fiddler crabs to the intertidal zone. Am. Zoologist, 8: 569-583.

Enright, J.T. 1963. The tidal rhythm of activity of a sand-beach amphipod. Z. vergl. Physiol., 46: 276-313.

Gibson, R.N. 1965. Rhythmic activity in littoral fish. Nature, 207: 544-545.

1969. Activity rhythms in two species of Blennius from the Mediterranean. Vie Milie, Sér A, 20: 235-244.

Honegger, H.W. 1973. Rhythmic motor activity responses of the California fiddler crab Uca crenulata to artificial light conditions. Mar. Biol., 18: 19-31.

Imafuku, M. 1973. On some physiological aspects in the daily rhythmic activity of the sea-pen, 
Cavernularia obesa Valenciennes. Publ. Seto Mar. Biol. Lab., 20 (Proc. Second Internat. Symp. Cnidaria): $431-454$.

Naylor, E. 1958. Tidal and diurnal rhythms of locomotory activity in Carcinus maenas (L.). J. Exp. Biol., 35: 602-610.

1960. Locomotory rhythms in Carcinus maenas (L.) from non-tidal conditions. J. Exp. Biol., 37: $481-488$.

: 1961. Spontaneous locomotor rhythm in mediterranean Carcinus. Pubbl. Staz. Z.ool. Napoli, 32: 58-63.

Palmer, J.D. 1974. "Biological Clocks in Marine Organisms". Wiley-Interscience: New York, London, Sydney, Tronto. 